\title{
Frequency of different symptoms in patients with COVID-19.
}

\footnotetext{
1. MBBS, FCPS

Assistant Professor Medicine

Bahria University Medical and Dental College.

2. MBBS, M.Phil, MAS

Professor Pathology

Bahria University Medical and Dental College.

3. MBBS, M.Phil

Assistant Professor Pathology Bahria University Medical and Dental College.
}

Correspondence Address:

Dr. Sehrish Shafique

Department of Medicine

Bahria University Medical and Dental

College.

drsehrish80@yahoo.com

Article received on:

04/11/2020

Accepted for publication:

19/01/2021

\begin{abstract}
Sehrish Shafique ${ }^{1}$, Naveed Faraz $^{2}$, Hina Wasti ${ }^{3}$
ABSTRACT... Objective: To find out the common symptoms in COVID -19 patients in association with age and gender. Study Design: Cross Sectional study. Setting: Study was conducted by approaching patients with COVID 19 positive in clinics, hospitals and those isolated at homes. Period: May 2020 to August 2020. Material \& Methods: This study was conducted in Karachi by filling up the proformas from patients diagnosed as COVID 19 during a period of 4 months. All the patients with 25 -75years of age, and diagnosed with COVID 19 positive were considered as a part of study. Data was written in a form of questionnaire.95\% confidence interval was taken. For entry of data SPSS version 20 was used. Results: A total of 150 cases were included after considering inclusion and exclusion criteria, among which 80(53.3\%) were males and $70(46.6 \%)$ were females. Most of the COVID -19 patients in our study between the age group of 61-75yrs (57\%) followed by 46-60yrs age group (30\%). This study also showed that fever and cough was among the commonly occurring symptoms in COVID-19 patients. Conclusion: Patient with different symptoms present in COVID-19 although cough and fever were the most common symptoms seen although few patient were symptoms free although COVID-19 positive.
\end{abstract}

Key words: Acute Respiratory Distress Syndrome, Contagious, Novel COVID 19, Pandemic.

Article Citation: Shafique S, Faraz N, and Wasti H. Frequency of different symptoms in patients with COVID-19. Professional Med J 2021; 28(7):931-935. https://doi.org/10.29309/TPMJ/2021.28.07.6196

\section{INTRODUCTION}

Corona virus is an RNA virus, which is highly contagious and that has caused pandemic all over the world. Its outbreak begins initially in December 2019 in China and manifested as pneumonia of unknown etiology that was confirmed later on investigations. ${ }^{1}$ And was designated as 2019-nCoV. Initially, it was named severe acute respiratory syndrome coronavirus 2 (SARS-CoV -2) due to genetic and clinical similarities to the severe acute respiratory syndrome coronavirus. ${ }^{2}$ However, the International Committee on Taxonomy of Viruses designated it as the SARS-CoV-2 virus 9. ${ }^{3}$ The World Health Organization (WHO) has named it as coronavirus disease-2019 (COVID-19) on February 11, 2020. In the beginning of March 2020, the worldwide cases confirmed by WHO were 87,317 which later on increased. ${ }^{4,5}$ Out Of these confirmed cases, 2,977 (3.42\%) patients have yielded the virus. The vast number of mortality has taken place in China that is $96.5 \%$. Most of the patients that are 79,968 (92\%) have been infected in China due to this virus. Other than China, 76169 cases also arise in 59 different countries. ${ }^{6}$ Due to the pandemic, the number of cases in involved countries varies in number. Most of the patients can have mild symptoms, yet $6 \%$ of cases were critically ill. Mortality rates can vary accordingly in different countries, but the WHO has estimated a global mortality of about $3 \%$ of confirmed cases. Pakistan was also highly affected due to the outbreak of virus in China. On the west side, Italy has the highest mortalities due to COVID 19 while, Iran was on second after Italy in mortality. In Our country the first case of COVID-19 have appeared on February 26, 2020 in Karachi, Sindh province which was confirmed by Health Ministry after which the number of (COVID-19 Positive) cases increased and reached to twenty (20) out of 471 
suspected cases with majority of cases to be in Sindh province followed by the Gilgit Baltistan. And presently these cases increase by high rate and the situation is worst. ${ }^{7}$

The mode of transmission of this virus is from animal-to-human and human to-human. It has an incubation period of 5-6 days. The clinical course of SARS-CoV-2 infection is different, comprising of asymptomatic infection, to mild upper respiratory tract illness, and severe viral pneumonia with respiratory failure and eventually ending in death. ${ }^{8,9}$ This virus can involve any system of the body, but mainly chest symptoms accounting for $5-10 \%$ of cases were more frequently seen presenting as pneumonias, and later as acute respiratory distress syndrome. ${ }^{10}$

Other organs which can be involved are brain, gastrointestinal tract and liver. ${ }^{11}$ It has been approximated that $2 \%-3 \%$ of the population are the healthy carriers of these viruses. ${ }^{12}$ Patients who have mild disease can present with symptoms of an upper respiratory tract viral infection. ${ }^{13}$ These include dry cough, mild fever, nasal congestion, sore throat, headache, myalgias, and malaise with absence of serious symptoms such as dyspneas. Around (81\%) of COVID-19 cases reported are mild in intensity and without any, radiograph signs of acute respiratory distress syndrome and pneumonias. ${ }^{14,15,16}$ Patients who have mild disease can quickly worsen into severe or critical disease and due to problem in breathing may need the ventilator support also. The aim of this study is to determine the occurrence of different symptoms in patients diagnosed as COVID 19 so help the patient to understand and not just to focus on conventional symptoms (Rationale of the study mentioned)

\section{MATERIAL \& METHODS}

The study was conducted by approaching patients with COVID 19 positive in clinics, hospitals and those isolated at homes. The duration of our study was 4 months from May 2020 to August 2020. It is a cross-sectional study. The study was commenced after the ethical approval taken from the ethical committee. Consent was taken from the patients prior to data collection after explaining the details of the study. Those patients diagnosed as COVID 19 positive between 25- 75 years of age irrespective of gender were included. They were given a questionnaire to fill in which they identified their symptoms. All the patients within 25-75 years of age, diagnosed and confirmed as COVID 19 positive were included in the study. Pregnant women, patients with history of any malignancies, hepatitis $\mathrm{B}$ and $\mathrm{C}$ and chronic renal failure patients were all excluded from the study. Data was collected in a pre-designed proforma. The total patients diagnosed with COVID positive will be presented by their frequencies and percentages with 95\% confidence interval.

\section{RESULTS}

Among 150 COVID 19 positive 80 (53\%) were males and $70(47 \%)$ were females. The ages vary between 25 till 75 years of age. Mostly COVID 19 positive cases in our study were between the age group of $61-75 y r s(57 \%)$.

Total Patients $=150$

Male $=80$

Female $=70$

\begin{tabular}{|l|c|c|}
\hline \multicolumn{1}{|c|}{ Symptoms } & Patients & $\%(\mathbf{n}=\mathbf{1 5 0})$ \\
\hline Cough & 110 & $73 \%(n=150)$ \\
\hline Fever & 120 & $80 \%(n=150)$ \\
\hline Sore Throat & 40 & $27 \%(n=150)$ \\
\hline Running Nose & 50 & $34 \%(n=150)$ \\
\hline Bodyaches & 45 & $30 \%(n=150)$ \\
\hline Breathlessness & 40 & $27 \%(n=150)$ \\
\hline NO Symptoms & 10 & $7 \%(n=150)$ \\
\hline Palpitation & 30 & $20 \%(n=150)$ \\
\hline Headache & 40 & $27 \%(n=150)$ \\
\hline
\end{tabular}

Table-I. Frequency of different symptoms among COVID-19 patient.

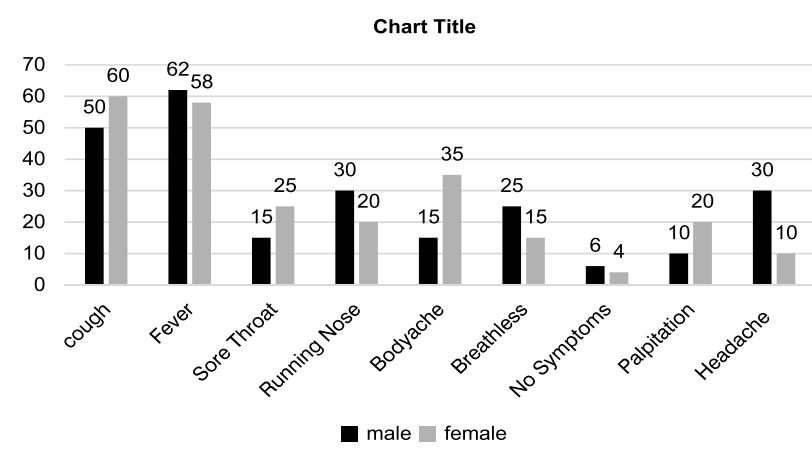

Figure-1. Frequency of different symptoms among COVID-19 patient according to gender difference. 


\begin{tabular}{|l|c|c|c|c|}
\hline & $\mathbf{2 0} \mathbf{- 3 0}$ yrs & $\mathbf{3 1 - 4 5}$ yrs & $\mathbf{4 6 - 6 0}$ yrs & $\mathbf{6 1 + y r s}$ \\
\hline Cough & 20 & 40 & 58 & 23 \\
\hline Fever & 16 & 24 & 17 & 10 \\
\hline Sore Throat & 3 & 10 & 25 & 10 \\
\hline Body Ache & 5 & 10 & 16 & nil \\
\hline Running Nose & 22 & 12 & 10 & 20 \\
\hline Breathlessness & 3 & 7 & 4 & 1 \\
\hline No Symptoms & nil & 5 & 13 & 10 \\
\hline Palpitation & 5 & 12 & 30 & 5 \\
\hline Headache & nil & 5 & & \\
\hline
\end{tabular}

Table-II. Frequency of different symptoms among COVID-19 patient in different age group.

\section{DISCUSSION}

It is shown from data of our study that fever is the frequent symptom in a patient with COVID-19 and 120 patient which comprises of $80 \%$ of total patient had complained of fever as their first symptoms whereas 10 patient were those who had no symptoms although they had reports that were positive for COVID-19 as shown in Table-I these finding are consistent with Miller $\mathrm{R}$, and .Guan $W$ et al in their previous studies. ${ }^{17,18} 110$ patients $(73 \%)$ had cough which is the second most common symptom that was identified by our target population also consistent with Chen $\mathrm{N}$, Zhou et al, Arentz M, et al. Kim ES et al in their studies. ${ }^{19,20,21}$

It is shown in our study that in female cough is the most common initial symptom whereas in male fever is the initial complain of COVID-19 patients .Interestingly 10 patient among both gender were those who although suffering from COVID19 but were free from symptoms and diagnosed incidentally during screening process as shown in Figure-1.

It is also shown in table 2 that in different age group fever was most commonly occurring symptom in age group 46-60 year i.e. 58 patient had fever, while cough is most commonly occurring symptom that effect the age group of $31-45 y r s$.In the age group of 20-30yr running nose is the most common feature of COVID19. In the age group above 60yrs fever and cough were the most common features. Breathlessness is not the initial complain of any age group while cough is the second common symptoms among age group of $46-60 y$ rs while no patient in an age group of 20-30yrs complaining of cough as the initial symptoms as shown in Table-II. These finding is consistent with Rodriguez-Morales AJ et al, Wang $X$ et al in their previous studies. ${ }^{22,23}$ It is shown from our study that there is no definite symptoms for COVID-19 patient with different symptoms and it differ in different age groups and gender but fever and cough were the most promising symptoms as compare to others symptoms which is consistence with $\mathrm{MJ}$, Baldwin MR, Abrams D, et al. ${ }^{24}$ So any patient who has suspected exposure they should have PCR testing done for the presence of virus in their body as few patients among our study were without any initial symptoms and they were diagnosed during screening procedure. Most importantly as the rate of infection transmission of COVID 19 is very high so if there is any doubt then go for screening instead of relying on symptoms of this disease as this virus can present with multiple symptoms and is difficult to conclude on the basis of symptom's and clinical examination.

\section{LIMITATION}

The main limitation of the study is a small sample size, this study can further be conducted on large scale In future as the incidence of cases with COVID 19 are increasing and presentation of symptoms can vary in patients.

\section{CONCLUSION}

This study conclude that patient with COVID-19 can present with variety of symptoms although cough and fever were the most common presenting symptoms, but few patient remained asymptomatic although COVID-19 positive .So if anyone who is suspected of having the infection 
or get in contact with COVID -19 patient so should have PCR lab investigation done for the confirmation of disease and don't rely on the symptoms only.

Copyright@ 19 Jan, 2021.

\section{REFERENCES}

1. Hassan S, Sheikh F N, Jamal S, Ezeh J, A. Coronavirus (COVID-19): A review of clinical features, diagnosis, and treatment. Cureus 2020; 12(3): e7355. DOI 10.7759 /cureus. 73551 .

2. Cascella M, Rajnik M, Cuomo A, Dulebohn SC, Napoli RD. Features, evaluation and treatment coronavirus (COVID-19). In: Stat Pearls [Internet]. Treasure Island (FL): Stat Pearls Publishing; 2020 Jan. 2020 Oct 4.

3. Fehr AR, Perlman S: Coronaviruses: An overview of their replication and pathogenesis. Methods Mol Biol. 2015; 1282:1-23.

4. Lu R, Zhao X, Li J, et al.: Genomic characterization and epidemiology of 2019 novel coronavirus: Implications for virus origins and receptor binding. Lancet. 2020; 395:565-574.

5. Chan JF, Kok KH, Zhu Z, Chu H, To KK, Yuan S, Yuen KY. Genomic characterization of the 2019 novel humanpathogenic coronavirus isolated from a patient with atypical pneumonia after visiting Wuhan. Emerg Microbes Infect. 2020; 9:221-236.

6. Vetter P, Lan Vu D, G Lhuillier A, Schibler M, Kaiser L, Jacquerioz. Clinical features of covid-19 the wide array of symptoms has implications for the testing strategy. BMJ 2020; 369:m1470 doi: 10.1136/bmj. $\mathrm{m} 1470$

7. Waris A, Khan A, Ali M, Ali A. COVID-19 outbreak: Current scenario of Pakistan. New Microbes and New Infection. May 2020; (35) C. DOI: 10.1016/j. nmni.2020.100681.

8. Zhou F, Yu T, Ronghui Du, Fan G, Liu Y, Zhibo Liu et.al. Clinical course and risk factors for mortality of adult inpatients with COVID-19 in Wuhan, China: $A$ retrospective cohort study. Lancet 2020; 395: 105462

9. Trilla A. One world, one health: The novel coronavirus COVID19 epidemic. Med Clin (Barc). 2020; 154(5):175177.

10. Keeley P, Buchanan D, Carolan C, Pivodic L. Symptom burden and clinical psystematic COVID 19 deaths. A systemic review and evidence summary. BMJ supportive and palliative care. May 2020;0:1-4
11. Ghinai I, McPherson TD, Hunter JC, Kirking HL, Christiansen $D$ et al.: First known person-to-person transmission of severe acute respiratory syndrome coronavirus 2 (SARS-CoV-2) in the USA. Lancet. 2020; (395) .

12. Li $Q$, Guan $X$, Wu $P$, Wang $X$, Zhou $L$ et al.: Early transmission dynamics in Wuhan, China, of novel coronavirus-infected pneumonia. N Engl J Med 2020; 382(13):1199-1207 DOI: 10.1056/NEJMoa2001316.

13. Wang $Y$, Chen $Y$, Qin $Q$ : Unique epidemiological and clinical features of the emerging 2019 novel coronavirus pneumonia (COVID-19) implicate special control measures. J Med Virol. 2020. 10.1002/ jmv.25748. doi: 10.1002/jmv.25748

14. Huang $\mathrm{C}$, Wang $\mathrm{Y}$, Li X, et al.: Clinical features of patients infected with 2019 novel coronavirus in Wuhan, China. Lancet. 2020; 395:497-506.

15. Wang $X$, Fang $X$, Cai $Z$, et al. Comorbid chronic diseases and acute organ injuries are strongly correlated with disease severity and mortality among COVID-19 patients: A systemic review and metaanalysis. Research (Wash DC) 2020; 2020:2402961. doi:10.34133/2020/2402961

16. Lai CC, Shih TP, Ko WC, Tang HJ, Hsueh PR. Severe acute respiratory syndrome coronavirus 2 (SARSCoV-2) and coronavirus disease-2019 (COVID-19): The epidemic and the challenges. Int $\mathrm{J}$ Antimicrob Agents. 2020; 55(3):105924.

17. Miller R, Englund $\mathrm{K}$. Clinical presentation and course of COVID-19. Cleveland Clinic Journal of Medicine. July 2020; 87 (7) 384-388.

18. Guan W, Ni Z, Yu Hu, Liang W, C. Ou, J. He.et.al. Clinical characteristics of coronavirus disease 2019 in China. New England journal medicine. April 30, 2020; 382:18.

19. Chen N, Zhou M, Dong $X$, et al. Epidemiological and clinical characteristics of 99 cases of 2019 novel coronavirus pneumonia in Wuhan, China: A descriptive study. Lancet 2020; 395: 507-13.

20. Arentz M, Yim E, Klaff L, et al. Characteristics and outcomes of 21 critically ill patients with COVID-19 in Washington State. JAMA. 2020 323(16):1612-14.

21. Kim ES, Chin BS, Kang CK, Kim N J, Kang YM, Choi JP et al. Clinical course and outcomes of patients with severe acute respiratory syndrome coronavirus 2 infection: A preliminary report of the first 28 patients from the Korean cohort study on COVID-19. J Korean Med Sci. 2020; 35(13):e142. 
22. Rodriguez-Morales AJ, Cardona-Ospina JA, GutiérrezOcampo $\mathrm{E}$, et al. Clinical, laboratory and imaging features of COVID-19: A systematic review and metaanalysis. Travel Med Infect Dis 2020; (March):101623. doi:10.1016/j.tmaid.2020.101623.
23. Wang $X$, Fang J, Zhu Y, et al. Clinical characteristics of noncritically ill patients with novel coronavirus infection (COVID-19) in a Fangcang Hospital. Clin Microbiol Infect. 2020; 26(8):1063-1068.

24. Cummings MJ, Baldwin MR, Abrams D, et al. Epidemiology, clinical course, and outcomes of critically ill adults with COVID-19 in New York City: A prospective cohort study. Lancet 2020; 395(10239):1763-1770.

\begin{tabular}{|c|l|l|l|}
\hline \multicolumn{3}{|c|}{ AUTHORSHIP AND CONTRIBUTION DECLARATION } \\
\hline Sr. \# & \multicolumn{1}{|c|}{ Author(s) Full Name } & \multicolumn{1}{|c|}{ Contribution to the paper } & Author(s) Signature \\
\hline 1 & Sehrish Shafique & $\begin{array}{l}\text { Introduction, Data collection, } \\
\text { Methodology. } \\
\text { Discussion, Compilation of } \\
\text { resutls, conclusion. } \\
\text { Review of literature, } \\
\text { references. }\end{array}$ \\
\hline 3 & Naveed Faraz & Hina Wasti & \\
\hline
\end{tabular}

